\title{
Sena Sakti (Sekolah Bencana; Siaga, Aksi dan Mitigasi)
}

\author{
Fahyumi Rahman ${ }^{1 *}$, Qo'idul Umam ${ }^{2}$ \\ ${ }^{1}$ Jurusan Pendidikan Geografi, Universitas Pendidikan Ganesha, Singaraja, Indonesia \\ ${ }^{2}$ Jurusan Pendidikan Geografi, Universitas Pendidikan Ganesha, Singaraja, Indonesia
}

\section{A R T I C L E I N F O \\ Article history: \\ Received 19 April 2018 \\ Accepted 28 Juni 2018 \\ Available online 30 Juni 2018 \\ Kata Kunci: \\ Komunitas; Sekolah Dasar; \\ Tanah Longsor \\ Keywords: \\ Community; Elementary \\ School; Landslide}

\begin{abstract}
A B S T R A K
Adapun tujuan penelitian ini adalah (1) Untuk menganalisis penanggulangan bencana tanah longsor berbasis komunitas sekolah dasar, (2) untuk menyusun strategi penyampaian pengetahuan dan keterampilan mitigasi bencana, (3) untuk mengetahui metode yang digunakan guru untuk memberikan pemahaman tentang bencana tanah longsor dalam pembelajaran. Metode yang digunakan dalam penulisan ini adalah pendekatan kualitatif dengan melakukan kajian melalui sumber empirik dan studi kepustakaan. Teknik pengumpulan data dilakukan dengan studi pustaka, studi dokumen, observasi dan wawancara kepada stakeholder terkait yaitu salah satu kepala sekolah dasar di Desa Gitgit. Hasil pembahasan menunjukkan bahwa penanggulangan bencana longsor di Sekolah Dasar dapat dilakukan dengan membentuk komunitas yang terdiri dari (1) agen sosialisasi bencana, (2) agen pertolongan pertama, (3) agen informasi dan komunikasi pasca bencana. sedangkan strategi pengetahuan dan keterampilan mtigasi bencana dilakukan dengan pelatihan
\end{abstract} keterampilan pertolongan pertama, pembentukan komunitas dan simulasi bencana. Pemahaman tentang bencana longsor diberikan kepada siswa dilakukan terintegrasi pembelajaran di kelas serta memasukkan peran kearifan lokal yang mendukung sebagai upaya dalam memanfaatkan kearifan lokal.

\section{A B S T R A C T}

The aim of this research are: (1) To analyze the prevention of landslide disaster based on elementary school communities, (2) to develop strategies for the transfer of knowledge and skill of disaster mitigation, (3) to know the method used by teacher to explain about landslide disaster in learning. The method used in this paper is a qualitative approach by conducting studies through empirical sources and literature studies. Technique of data collecting is done by literature study, document study, observation and interview to related stakeholder that is one of principal of elementary school in Gitgit Village. The results of the discussion show that the prevention of landslide disaster in elementary school can be done by forming community consisting of (1) disaster dissemination agent, (2) first aid agent, (3) information and communication agent after disaster. while knowledge strategies and skills for disaster mitigation are conducted with first-aid skills training, community building and disaster simulation. Understanding of landslide disaster provided to students is integrated in classroom learning and incorporates the role of local wisdom in support of local wisdom.

Copyright (C) Universitas Pendidikan Ganesha. All rights reserved.

\section{Pendahuluan}

Bencana alam berdampak sangat kompleks pada setiap aspek kehidupan baik dari segi ekonomi, sosial dan kesehatan. Salah satu bencana alam yang disebabkan karena faktor alam dan faktor manusia yaitu tanah longsor (landslide). Tanah longsor mengakibatkan perubahan pada lahan maupun pada kondisi lingkungan yang terjadi di area tanah longsor.

\footnotetext{
Corresponding author.

E-mail addresses: fahyumirahman29@gmail.com, qoidulu@gmail.com
} 
Bencana alam tanah longsor merupakans suatu pergerakan massa tanah pada bidang lereng yang mengakibatkan terangkutnya material yang ada pada lereng sampai ke area lereng terendah dalam kurun waktu tertentu. Hal tersebut terjadi dikarenakan permukaan lereng yang tidak terdapat vegetasi, sehingga tidak adanya penahan pergerakan massa tanah yang diakibatkan oleh curah hujan (presipitasi) yang terjadi secara terus-menerus.

Selain itu faktor lain yang menyebabkan longsor yaitu alih fungsi lahan, dan sistem pertanian yang tidak sesuai di daerah lereng sehingga dampak yang ditimbulkan oleh bencana alam tanah longsor dapat menutup ruas jalan, permukiman, maupun gedung sekolah dan dapat menimbulkan bencana banjir bandang bila tidak segera diatasi.

Fenomena bencana alam tanah longsor sering terjadi di wilayah Bali bagian Utara, tepatnya di Kabupaten Buleleng. Kabupaten Buleleng adalah salah satu kabupaten di Provinsi Bali yang memiliki garis pantai terpanjang. Wilayah kabupaten buleleng sangat bervariatif dalam hal fisiografis mulai dari wilayah pesisir sampai daerah perbukitan (Upland). Dilihat dari geomorfologinya wilayah Bali utara dan Bali selatan dibatasi oleh perbukitan yang membentang dari barat hingga timur, sehingga jalur penghubung antara Bali bagian utara dan selatan harus melewati lereng pegunungan yang curam dan rawan longsor ketika musim penghujan tiba.

Tak jarang, pengendara yang melalui jalur singaraja-Denpasar korban bencana alam tanah longsor. Selain itu seluruh lapisan masyarakat juga beresiko menjadi korban bencana tersebut. Tetapi, yang lebih beresiko tinggi terkena imbas dari tanah longsor yaitu anak-anak dikarenakan lokasi sekolah mereka terletak pada lereng perbukitan yang terjal.

Salah satu daerah rawan longsor yaitu berada di Kecamatan Sukasada, tepatnya di Desa Gitgit. Desa yang terletak di daerah dataran tinggi ini rawan terjadi longsor yang setiap kali menutup akses jalan penghubung antar kabupaten, merusak bangunan rumah, sekolah, serta fasilitas penerangan yang terdapat diruas jalan, bahkan sampai menelan korban jiwa.

Kecamatan Sukasada, dalam beberapa tahun terakhir mengalami kejadian tanah longsor. Bencana tanah longsor menyebabkan korban jiwa, rumah rusak, rusaknya lahan pertanian penduduk dan tertimbunnya badan jalan sehingga arus transportasi menjadi terputus. Berikut ini adalah beberapa kejadian bencana tanah longsor di Kecamatan Sukasada (Badan Penanggulangan Bencana Daerah [BPBD] Provinsi Bali, 2014):

- Tanah longsor di Desa Pancasari pada 2 Pebruari 2012 menyebabkan 2 orang meninggal, 1 orang luka, 1 rumah rusak.

- Tanah longsor di Desa Gitgit 19 Pebruari 2013 menyebabkan 2 orang meninggal dunia.

- Tanah longsor di Desa Sambangan 15 Desember 2013 menyebabkan 3 orang meninggal dunia.

- Tanah longsor di Desa Padangbulia 24 April 2014 menyebabkan tertimbunnya saluran irigasi dan badan jalan.

- Tanah longsor terakhir mengakibatkan longsor di 12 titik di jalur. Longsor terparah ada di tiga titik, yakni di kilometer 14, 16, dan 17 (12 Februari 2017)

Upaya dalam menekan jumlah korban akibat tanah longsor, maka masyarakat perlu dibekali untuk melakukan kesiapsiagaan terhadap bencana alam tanah longsor, terutama pada komunitas sekolah Dasar. Hal ini dilakukan, Apabila tanah longsor terjadi pada jam belajar di sekolah, maka dibutuhkan suatu tindakan yang tepat agar dampak terjadinya tanah longsor pada komunitas Sekolah Dasar dapat diminimalisir. Hal tersebut dapat diwujudkan melalui pelatihan yang melibatkan komunitas Sekolah Dasar.

\section{Metode}

Penulisan ini dilakukan dengan menggunakan pendekatan kualitatif dengan melakukan kajian melalui sumber empirik dan studi kepustakaan. Adapun teknik pengumpulan data dilakukan dengan studi pustaka, studi dokumen, observasi dan wawancara kepada stakeholder terkait yaitu salah satu kepala sekolah dasar di Desa Gitgit. Analisis data menggunakan reduksi data dan triangulasi yang kemudian di analisis secara deskriptif. 


\section{Hasil dan pembahasan \\ Penanggulangan Bencana Tanah Longsor Berbasis Komunitas Sekolah Dasar}

Pada tahun 2006, hasil penelitian dari Lembaga Ilmu Pengetahuan Indonesia (LIPI) dan bekerjasama dengan United Nations Educational, Scientific and Cultural Organization (UNESCO) menyatakan bahwa kesiapsiagaan bencana untuk sekolah adalah paling rendah dibandingkan dengan kesiapsiagaan rumah tinggal dan Masyarakat di Indonesia (LIPI: 2007 dalam Lesmana dan Purborini, 2015). Beberapa daerah di Indonesia sangat rentan terjadi bencana alam yang jenisnya bervariasi sesuai keadaan fisiografis daerah. Dampak resiko bencana alam selain berimbas pada permukiman masyarakat, akses jalan, dan lahan pertanian juga berdampak pada sekolah yang berada pada daerah rawan bencana alam. Sekolah merupakan komponen penting dalam menunjang peningkatan kualitas Sumber Daya Manusia sehingga komunitas sekolah harus memiliki kesadaran dan kesiapsiagaan dalam mengantisipasi dampak resiko bencana alam tanah longsor.

Penanggulangan bencana yang baik harus terintegrasi ke dalam sektor pendidikan, karena pendidikan menjadi salah satu faktor penentu dalam kegiatan pengurangan risiko bencana. Kegiatan pengintegrasian ini bisa dimulai sejak dini dimulai yaitu anak-anak di jenjang TK-SD sampai jenjang SMP-SMA. (Arifianti, 2011). Pemberian pemahaman terkait pengurangan risiko bencana sejak dini adalah suatu hal yang sangat penting dilakukan mengingat bencana alam sewaktu-waktu dapat terjadi di setiap daerah di Indonesia yang salah salah satunya di Kabupaten Buleleng yang rawan bencana alam tanah longsor. Karakteristik topografi yang didominasi oleh kawasan perbukitan beresiko tinggi terjadinya bencana alam tanah longsor, sehingga untuk meminimalisir korban bencana alam tanah longsor yang dapat menimpa Sekolah Dasar pada kawasan Upland maka harus dilakukan suatu cara strategi untuk memberikan pemahaman terkait dengan mitigasi bencana alam tanah longsor pada komunitas Sekolah Dasar.

Penyuluhan dan pelatihan mitigasi bencana alam tanah longsor pada Komunitas Sekolah Dasar sangat penting dilakukan untuk menumbuhkan kesiapsiagaan dan adaptasi terhadap kawasan bahaya bencana alam tanah longsor. Kaitannya dengan hal ini, seluruh elemen yang terdapat di sekolah dasar dilibatkan dalam mengantisipasi dan meminimalisir resiko terjadinya bencana dengan membentuk 3 Agen pada Komunitas Sekolah Dasar yaitu sebagai berikut:

\section{Agen sosialisasi bencana alam tanah longsor}

Komunitas ini bergerak pada langkah preventif atau antisipasi guna memberikan pengetahuan dan pemahaman terkait mitigasi bencana alam tanah longsor. Komunitas ini terdiri dari siswa kelas IV, V dan VI serta 2 orang dari staf guru. Komunitas ini memiliki perananan dalam mensosialisasikan langkah mitigasi bencana alam tanah longsor di sekolah serta ditunjang oleh guru yang menyampaikan pengetahuan dan keterampilan terkait mitigasi bencana dalam pembelajaran. Adapun kegiatan yang dilakukan oleh komunitas ini yaitu pencegahan dan meminimalisir terjadinya bencana alam tanah longsor di sekolah dasar, seperti melakukan sosialisasi terhadap siswa lainnnya, penyampaian dalam pembelajaran, menanam dan merawat pohon di sekitar lingkungan sekolah serta kegiatan lainnya yang dilakukan untuk meminimalisir dampak terjadinya Bencana alam tanah longsor.

\section{Agen Pertolongan Pertama Pasca bencana}

Komunitas ini memiliki peranan dalam melakukan mitigasi pasca bencana tanah longsor yaitu melakukan pertolongan pertama untuk meminimalisir terjadinya korban jiwa. Komunitas ini terdiri dari sebagian besar yaitu jajaran guru yang telah diberikan keterampilan Pertolongan Pertama Gawat Darurat (PPGD). Keterampilan yang dimiliki komunitas ini yaitu diantaranya cara evakuasi korban, penanganan syok dan pendarahan, dan cedera otot rangka.

\section{Agen informasi dan komunikasi pasca bencana}

Komunitas ini memiliki peranan dalam menyampaikan informasi dan komunikasi terhadap Instansi yang menangani masalah bencana seperti BPBD dan PMI Kabupaten Buleleng. Serta mengkomunikasikan kepada komunitas sekolah dasar untuk segera dievakuasi ke tempat yang lebih aman dan bersikap tanggap jika terdapat korban pada komunitas sekolah yang harus segera dilakukan penanganan medis. Sehingga pola penanganan korban pasca bencana alam 
tanah longsor akan lebih terstruktur dan memberikan respon cepat untuk tanggap darurat bencana.

\section{Strategi Penyampaian Pengetahuan dan Keterampilan Mitigasi Bencana}

Pembelajaran sebagai suatu sistem merupakan pengorganisasian berbagai komponen dalam upaya mengubah siswa mencapai suatu kondisi yang lebih meningkat secara positif. Untuk mencapai sasaran pembelajaran dibutuhkan banyak persyaratan menyangkut materi, dalam hal ini materi yang meliputi bahan ajar atau medianya (Sutjiono, 2005 dalam Arifianti, 2011). Penyampaian pengetahuan mitigasi bencana alam tanah longsor pada siswa kelas 4,5 dan 6 yaitu menggunakan media modul dengan ilustrasi yang berkaitan mitigasi bencana tanah longsor yang selanjutnya digunakan oleh Guru dan Siswa sebagai media pembelajaran di kelas.

Rendahnya pemahaman Siswa di sekolah dasar terkait dengan langkah pengurangan risiko bencana alam tanah longsor karena penggunaan minimnya penggunaan media pembelajaran yang konvensional, dan tidak dikemas dalam media yang mudah dipahami dengan banyak ilustrasi. Kemudian, pemilihan isi dan gaya penyampaian pesan mempunyai tujuan memberikan motivasi kepada anak-anak. Selain itu harus menstimulus siswa dalam memproses apa yang dipelajari serta memberikan rangsangan belajar baru. Terakhir, bisa mengaktifkan anak dalam memberikan tanggapan, feedback dan juga mendorong anak-anak untuk melakukan praktikpraktik dengan benar. Agar media pembelajaran bermanfaat secara optimal, maka dipilih media yang tepat, Modul dengan ilustrasi menarik merupakan media yang tepat karena memenuhi unsur-unsur tersebut.

Adapun rangkaian Penyampaian dan Pembentukan agen mitigasi bencana alam tanah longsor berbasis komunitas sekolah dasar yaitu sebagai berikut:

1. Penyampaian Informasi dan tanya jawab tentang ruang lingkup bencana alam tanah longsor, faktor penyebab, Tindakan saat terjadi tanah longsor dan dampaknya. Dilanjutkan diskusi kelompok peserta untuk merencanakan tindakan kesiapsiagaan menghadapi bencana tanah longsor.

2. Keterampilan pertolongan pertama pada korban tanah longsor oleh meliputi: Evakuasi Korban, Penanganan Syok dan Pendarahan serta Cedera Otot Rangka (COR). Setiap materi pelatihan diikuti praktek oleh Komunitas Sekolah Dasar.

3. Pembentukan Komunitas Sekolah Dasar yang memiliki fungsi dan peranan masing-masing dalam meminimalisir terjadinya dampak bencana alam tanah longsor

4. Simulasi dan menentukan jalur evakuasi di sekolah

Penyampaian dan pelatihan terkait dengan langkah pengurangan resiko bencana, disampaikan melalui pembelajaran sebaya dengan menggunakan media pembelajaran dengan nuansa ilustrasi kebencanaan dalam bentuk modul kebencanaan supaya memudahkan dalam memahami pengetahuan dan keterampilan yang menunjang dalam meminimalisir dampak resiko bencana. Setelah penyampaian dan pelatihan maka akan dipilih pengelompkan untuk membentuk tiga komunitas yang memiliki perananan masing-masing dalam meminimalisir dampak resiko bencana alam tanah longsor.

\section{Metode yang digunakan guru untuk memberikan pemahaman tentang bencana tanah longsor dalam pembelajaran}

Model pembelajaran dikemas dan diintegrasikan ke dalam kurikulum sekolah yang dilaksanakan mulai pada jenjang pendidikan dasar dengan alasan, 1). Hasil pendidikan bersifat tahan lama dan berjangka panjang, 2). Menjangkau populasi yang cukup besar untuk masa depan bangsa, dan 3). Merupakan masa yang sangat tepat untuk menyemaikan nilai-nilai sosiomoral kepada peserta didik (Rusilowati dkk, 2012).

Materi bencana alam yang akan disampaikan yaitu mengenai mitigasi bencana tanah longsor yang dimulai dari sebelum bencana, bencana dan pasca bencana tanah longsor. Penyampaian materi dilakukan dengan menyusun perencanaan pembelajaran yang nantinya materi kebencanaan ini akan diintegrasikan dengan pelajaran. Materi mengenai mitigasi bencana tanah longsor ini dapat di integrasikan dengan pelajaran-pelajaran tersebut sesuai dengan KD yang telah ada namun akan ditambahkan mengenai materi kebencanaan pada 
indikator. Misalkan pada materi IPS bisa di integrasikan dengan standar kompetensi mengenai kenampakan alam, mengenal kenampakan alam dan kenampakan buatan serta ada standar kompetensi mengenai kebencanaan pada kelas VI (Afandi, 2013). Pada materi IPA bisa diintegrasikan dengan bahan ajar struktur akar tumbuhan dan fungsinya, penyesuaian diri tumbuhan terhadap lingkungannya serta materi pelapukan (Rusilowati dkk, 2012).

Sedangkan pada materi bahasa Indonesia kebencanaan bisa diintegrasikan dengan menggunakan materi sastra fiksi dan non-fiksi. Misalkan pada novel, puisi, dan komik. Penelitian yang dilakukan oleh Else Liliani pada tahun 2010 mengatakan bahwa tema dan pesan moral adalah sarana yang paling efektif untuk dimanfaatkan sebagai media mitigasi bencana. Tema adalah inti atau gagasan pokok yang ada dalam karya sastra. Pesan moral dalam teks mengacu pada "apa yang sebaiknya dilakukan oleh pembaca" setelah membaca teks itu. Kedua unsur ini hampir ditemui di semua jenis sastra yang dikaji. Berikut merupakan alur yang digunakan dalam tahap merumuskan materi pembelajaran yang akan digunakan untuk menjelaskan materi mitigasi bencana alam tanah longsor. Pemberian materi mengenai mitigasi bencana alam tanah longsor ini diharapkan agar peserta didik bisa lebih tanggap dengan bencana. Hal tersebut dikarenakan kebanyakan peserta didik yang menempuh pendidikan di SDN 3 Gitgit bermukim di daerah yang rawan bencana longsor. Melalui materi ini diharapkan peserta didik bisa menyelamatkan dirinya jika terjadi bencana tanah longsor.

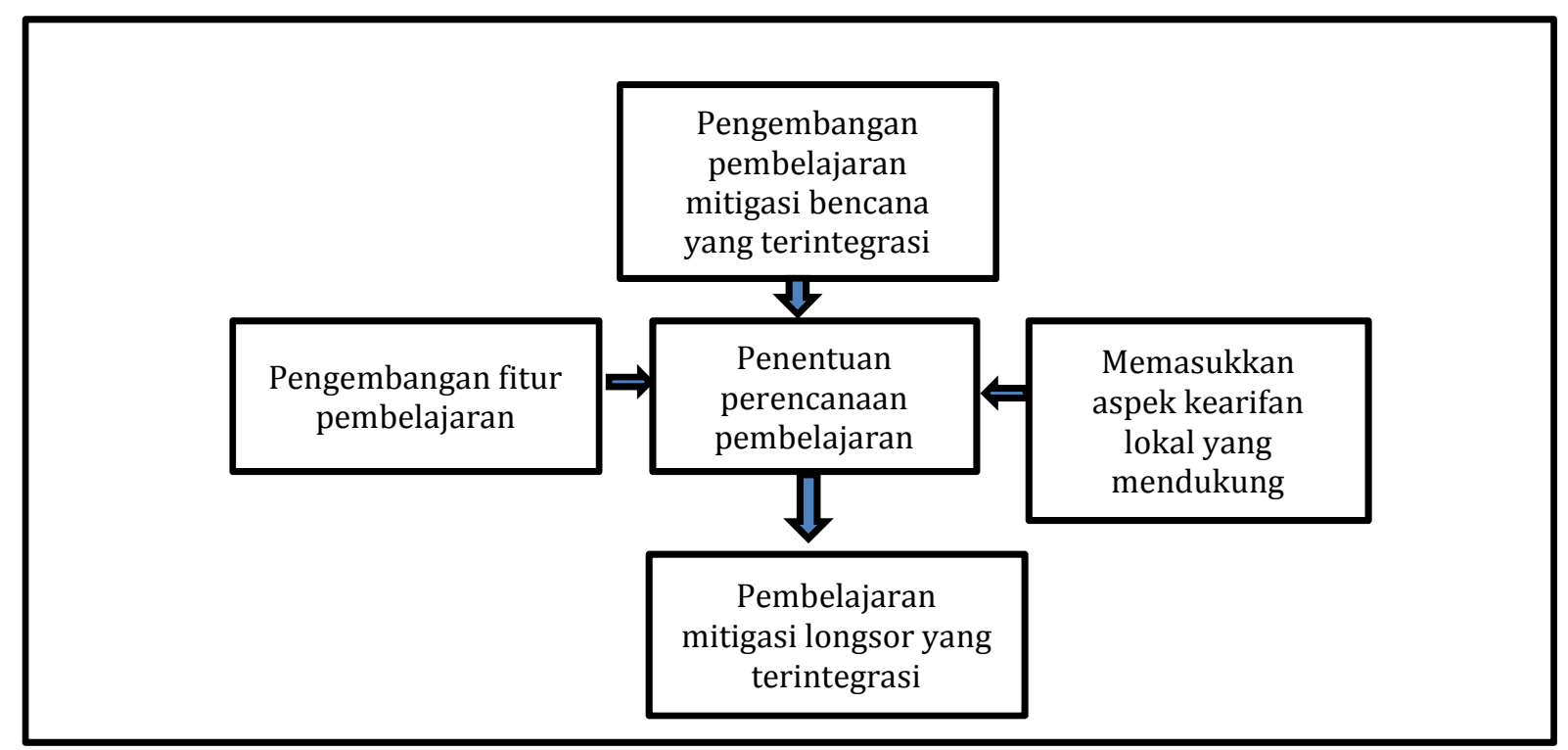

Gambar 1. Model Pengembangan Mitigasi Bencana Berbasis Pembelajaran

Gambar 1 menjelaskan alur pembelajaran yang berbasis mitigasi bencana pada siswa sekolah dasar, adapun penjelasan bagan mitigasi bencana berbasis pembelajaran yaitu Pengembangan pembelajaran mitigasi bencana dilakukan dengan cara integrasi dengan mata pelajaran yang ada di sekolah dasar. Setelah itu dilakukan perencanaan pembelajaran yang akan digunakan untuk menyampaikan materi mengenai mitigasi bencana tersebut baik itu berupa materi maupun adanya simulasi mengenai bencana tanah longsor.

Perencanaan pembelajaran ini dilakukan sesuai dengan aspek kearifan lokal yang ada di sekolah. Kearifan lokal Bali yang bisa dimasukkan dalam perencanaan ini adalah Tri Hita Karana, yaitu tiga penyebab kesejahteraan. Bagian dari Tri Hita Karana itu adalah hubungan antara manusia dengan Tuhannya, hubungan manusia dengan lingkungannya dan hubungan manusia dengan sesamanya.

Pengintergrasian konsep Tri Hita Karana diharapkan para siswa mampu menjaga kelestarian lingkungannya untuk mencegah terjadinya becana. Pada perencanaan pembelajaran ini juga akan disusun mengenai fitur yang akan digunakan dalam pembelajaran. Fitur pembelajaran ini nantinya akan digunakan untuk menyampaikan materi mengenai migasi bencana akam tanah longsor ini. Setelah perencaan pembelajaran disusun, langkah selanjutnya yaitu implementasi pembelajaran di dalam kelas. 


\section{Simpulan dan saran}

Berdasarkan dari uraian pembahasan, maka dapat diambil simpulan bahwa; Strategi untuk menumbuhkan kesiapsiagaan dan adaptasi terhadap sekolah yang berlokasi pada daerah rawan bencana alam tanah longsor adalah dengan pelatihan dan pembentukan kader mitigasi bencana alam berbasis Komunitas Sekolah Dasar. Dalam hal ini, seluruh element yang terdapat di sekolah dasar dilibatkan dalam mengantisipasi dan meminimalisir resiko terjadinya bencana dengan membentuk 3 agen dalam Komunitas Sekolah Dasar yaitu 1) Agen Sosialisasi Bencana, 2) Agen PPGD pasca bencana, 3) Agen Informasi dan Komunikasi pasca bencana. Dalam memberikan pengetahuan dan pemahaman terkait mitigasi bencana alam tanah longsor pada siswa kelas 4,5 dan 6 digunakan media modul dengan ilustrasi yang berkaitan mitigasi bencana tanah longsor yang selanjutnya digunakan oleh siswa sebagai media pembelajaran di kelas. Penyampaian dan Pembentukan agen mitigasi bencana alam tanah longsor berbasis komunitas sekolah dasar yaitu sebagai berikut: 1) Penyampaian materi bencana alam tanah longsor, 2) Pelatihan Evakuasi dan PPGD, 3) Pembentukan Agen mitigasi bencana pada Komunitas Sekolah Dasar, 4) Simulasi dan membuat jalur evakuasi di sekolah. Metode yang digunakan dalam guru dalam menyampaikan materi tentang mitigasi bencana longsor dilakukan secara terintegrasi dalam pembelajaran sehari-hari. Hal ini dapat dilakukan dengan menyusun perencanaan pembelajaran dengan memasukkan aspek-aspek kearifan lokal yang mendukung serta mengembangkan fitur pembelajaran yang berkaitan dengan mitigasi bencana longsor

Adapun saran yang dapat peneliti berikan sebagai berikut: Bagi kepala Sekolah Dasar, agar selalu mengembangkan metode pembelajaran yang menarik dalam menyampaikan materi mitigasi bencana khususnya tanah longsor agar dapat menanamkan karakter sadar bencana kepada siswa-siswa. Bagi pemerintah atau dinas terkait, dapat digunakan sebagai formulasi baru dalam mengembangkan metode mitigasi bencana berbasis komunitas sekolah dasar sebagai langkah preventif dalam menanggulangi bencana khususnya bencana longsor. Bagi penelitian selanjutnya, agar mampu melakukan penelitian dalam kajian lain, melihat potensi buleleng dalam sektor kebencanaan masih sangat banyak.

\section{Daftar Rujukan}

Arifianti, Yukni. 2011. Buku Mengenal Tanah Longsor Sebagai Media Pembelajaran Bencana Sejak Dini. Bulletin Vulkanologi dan Bencana Geologi, Volume 6 Nomor 3, Desember 2011: 17-24.

Badan Penanggulangan Bencana Daerah Provinsi Bali. 2014. Laporan Bencana Bulanan Provinsi Bali. Badan Penanggulangan Bencana Daerah Provinsi Bali.

Dwikorita Karnawati. 2005. Bencana Alam Gerak Massa Tanah di Indonesia dan Upaya Penanggulangannya. Yogyakarta: Universitas Gajah Mada.

LIPI - UNESCO/ISDR. 2006. Kajian Kesiapsiagaan Masyarakat dalam Mengantisipasi Bencana Gempa Bumi dan Tsunami. Jakarta: Lembaga Ilmu Pengetahuan Indonesia.

Lesmana, Cindrawaty dan Nurul Purborini. 2015. Kesiapsiagaan Komunitas Sekolah dalam menghadapi bencana di kabupaten Magelang. Jurnal Teknik Sipil, Volume 11 Nomor 1, April 2015: 1-75

Undang-Undang Republik Indonesia Nomor 24 Tahun 2007 tentang Penanggulangan Bencana.

Setyawan, Dodiet Aditya. 2012. "Konsep Dasar Masyarakat. Makalah disajikan dalam MK. ASKEB KOMUNITAS II. Jurusan Kebidanan Poltekkes Kemenkes Surakarta. 6 Februari 2012.

Afandi, Rifki. 2013. Integrasi Pendidikan Lingkungan Hidup Melalui Pembelajaran IPS di Sekolah Dasar sebagai Alternatif Menciptakan Sekolah Hijau. Sidoarjo: Universitas Muhammadiyah Sidoarjo

Rusilowati, Supriyadi, Binadja, Mulayani. 2012. Mitigasi Bencana Alam Berbasis Pembelajaran Bervisi Sciense Environment Technology and Society. Semarang: Universitas Negeri Semarang.

Liliani, Else. 2010. Pemanfaatan Sastra Anak Sebagai Media Mitigasi Bencana. Universitas Negeri Yogyakarta. 